\section{Fatores Envolvidos no Pico de Massa Óssea}

RESUMO

A massa óssea de um indivíduo adulto, que está estreitamente relacionada ao risco de fraturas osteoporóticas, depende da diferença entre o pico de massa óssea alcançado no final do período de maturação sexual e esquelética, e as perdas acumuladas durante a vida. A enorme variabilidade observada no pico de massa óssea da adolescência está relacionada, principalmente, a fatores genéticos, mas também a parâmetros antropométricos, como peso e altura, hábitos dietéticos, influências hormonais diversas, atividade física, uso de medicamentos e doenças intercorrentes. A identificação dos fatores envolvidos na aquisição do pico de massa óssea na infância e adolescência e a compreensão deste longo período de maturação esquelética, permitirão a criação de estratégias para prevenção da osteoporose. (Arq Bras Endocrinol Metab 1999:43/6: 401-408)

Unitermos: Pico de massa óssea; Densidade mineral óssea em crianças e adolescentes

\begin{abstract}
Bone mass in the adult life, which is closely related to osteoporotic fracfure risk, depends on the differences between the peak bone mass attained at the end of the sexual and skeletal maturation and the rate of involutional bone mass. The great variability in peak bone mass observed at adolescence is related not only to genetic factors, but also to diet, hormonal status, anthropometric variables, as weight and height, physical activity, drugs and intercurrent diseases. The identification of the factors involved with the acquisition of the peak bone mass and the comprehension of this long period of skeletal maturation will indicate strategies for prevention of osteoporosis. (Arq Bras Endocrinol Metab 1999:43/6: 401-408)
\end{abstract}

Keywords: Peak bone mass; BMD in children and adolescents

\footnotetext{
A INCIDÊNCIA DE FRATURAS OSTEOPORÓTICAS está estreitamente relacionada à massa óssea do indivíduo, que depende tanto da velocidade de perda durante a vida quanto da quantidade de tecido ósseo presente no final da puberdade e início da vida adulta. A enorme variância no pico de massa óssea é explicada năo só por fatores hereditários, como também por sexo, raça, hábitos dietéticos, atividade física, influências hormonais diversas, composição corporal de massa magra e gordurosa, doenças intercorrentes, uso crônico de medicamentos. A compreensão do longo processo de maturação óssea que ocorre na infầncia e adolescência vai permitir identificar os fatores passíveis de alguma intervenção e a criação de estratégias para prevenção precoce da osteoporose. Se o ganho mineral ósseo puder ser otimizado durante a puberdade, é provável que o indivíduo adulto esteja menos susceptível a sofrer as devastadoras complicações da osteoporose.
}

revisão

\author{
Cynthia M.A. Brandão \\ José Gilberto H. Vieira
}

\author{
Disciplina de Endocrinologia e \\ Metabologia, Universidade Federal de \\ São Paulo-Escola Paulista de \\ Medicina (UNIFESP-EPM), SP
}


O desenvolvimento, nesses últimos dez anos, de métodos para avaliar a massa óssea com acurácia e precisão, não-invasivos e com mínima exposição à radiação, permitiu uma melhor compreensão da dinâmica do tecido ósseo (1-6) na infầncia e adolescência. No entanto, a complexa inter-relaçăo dos fatores envolvidos com o pico de massa óssea ainda se mantêm pouco estudada, por dificuldades metodológicas e conceituais. Por exemplo, a densitometria por DxA, que é o método de escollha para o estudo da massa óssea na população pediátrica, apresenta uma inacurácia $\mathrm{em}$ relação à densidade volumétrica real, pois é calculada considerando-se apenas duas dimensões das vértebras (densidade por área, $\mathrm{g} / \mathrm{cm}^{2}$ ). A terceira medida, de profundidade das vértebras, pode ser avaliada através do exame lateral, mas não é uma medida acurada como a fornecida pela tomografia computadorizada, pois a vértebra não é um cubo perfeito, apresentando superficies côncavas de difícil detecção para a densitometria. Numa avaliação longitudinal de crianças, o crescimento das vértebras vai obscurecer o ganho de densidade mineral, ou seja, para uma densidade óssea constante, vértebras maiores resultarão em maiores valores de BMD.

Outro aspecto a ser lembrado é a significativa variabilidade dos parâmetros antropométricos e de maturação sexual entre crianças de uma mesma idade cronológica. Para avaliar efetivamente a massa óssea de uma criança e particularmente de um adolescente, todos os fatores envolvidos no ganho de massa óssea devem ser considerados e não apenas a idade cronológica.

\section{FATORES ENVOLVIDOS NA AQUISIÇĀO DA MASSA ÓSSEA NA PUBERDADE}

\section{Genética}

Têm havido grande interesse no estudo dos fatores genéticos envolvidos no metabolismo ósseo e na fisiopatologia da Osteoporose. Os trabalhos tradicionais observam a ocorrência de agregação familiar de menor massa óssea e a concordância deste traço em gêmeos mono e dizigóticos (7-14). Howard et al. (12) demonstraram que grande parte da variância dos parâmetros avaliados pelo ultra-som ósseo, cerca de $80 \%$, pode ser atribuída à fatores genéticos, do mesmo modo que $70-80 \%$ da densidade mineral óssea $(15,16)$. Além disso, alguns fatores genéticos parecem ser comuns na determinação tanto da densidade mineral quanto das medidas fornecidas pelo ultra-som, que refletem a integridade da microarquitetura óssea.

A determinação genética da densidade mincral óssea pode ser mediada por polimorfismos do DNA de genes relacionados à remodelação e particularmente à formação óssea. Dois estudos $(17,18)$, em gêmeos mono e dizigóticos, demonstraram claramente que uma grande parte da variância dos marcadores de reabsorção, assim como de reabsorção óssea, particularmente osteocalcina, é geneticamente determinada e este fenômeno contribui para a regulação genética da densidade mineral óssea.

Em um estudo com gêmeos, Morrison et al. (19), na Austrália, observaram valores baixos de densidade mineral óssea em mulheres homozigotas para a ausência de restrição BsmI no gene do receptor da vitamina $D$, comparados aos valores de mulheres homozigotas para a presença do sítio de restrição. Inúmeros trabalhos subsequentes associaram esta variação com a massa óssea na pré-menopausa (20-22) e com a velocidade de perda óssea durante a vida $(23,24)$. Estes estudos sugerem que o genótipo do receptor da vitamina $D$ influencie o transporte de cálcio intestinal, a incorporação do mineral ao esqueleto, a resposta à ingesta nutricional durante o crescimento e o recrutamento celular.

No entanto, outros trabalhos mostraram resultados conflitantes (25-28), enfraquecendo a importância do polimorfismo do gene da vitamina $\mathrm{D}$ na gênese da Osteoporose. Diferenças raciais, étnicas e ambientais entre as populações estudadas e o envolvimento de outros genes (herança poligênica) podem estar contribuindo para esta discordância de resultados (29).

Em nosso meio, os estudos que avaliaram o polimorfismo do gene da vitamina $D$ apresentaram resultados semelhantes aos da literatura, ou seja, dependendo das características da população estudada se observa ou não a associação com menor massa óssea Castro et al. (30), em. um estudo feito em uma população de mulheres normais na pré-menopausa, observaram uma correlação negativa entre a BMD de coluna lombar e fềmur e a presença do genótipo BB, em relação ao genótipo bb, utilizando-se a enzima de restrição Bsml. O mesmo grupo, em dois outros trabalhos $(31,32)$, não encontrou uma prevalência maior do genótipo associado à menor massa óssea (BB) numa população de idosos com fraturas femurais nem a osteopenia observada em diabéticos insulino-dependentes estava relacionada ao polimorfismo.

Receptores estrogênicos foram identificados em inúmeros tipos celulares, inclusive osteoblastos, havendo uma interação com a massa óssea (33-35). Os estrogênios regulam a proliferação celular e a expressão dos marcadores de remodelação óssea, dos fatores de crescimento, citoquinas e de outros receptores como de IGF-I, Interlencina 6 e progesterona (36). Em 1994, Smith et al. (37) descreveram um 
homem com resistência estrogênica por apresentar uma mutação no gene do receptor estrogênico tipo alfa, com níveis plasmáticos elevados de cstrógenos e gonadotrofinas. O paciente, de 29 anos, apresentava osteoporose e atraso na maturação esquelética, demonstrando a importância do estrógeno na mineralização óssea tanto em mulheres quanto em homens.

O estudo dos receptores estrogênicos e a observação de seu polimorfismo genético, abriram um amplo campo de pesquisa. Muitos trabalhos correlacionam este polimorfismo com o câncer de mama, abortos de repetição, hipertensão arterial c com a densidade mineral óssea (34). A associação de valores menores de BMD com determinadas variações genotípicas do receptor estrogênico parece se correlacionar com o pico de massa óssea alcançado na puberdade ou com diferenças significativas no padrão de perda óssea durante a vida.

Além disso, outros genes também foram associados ao metabolismo ósseo, como o da calcitonina, IGF-I, colágeno tipo I e II, genes da família dos "Transforming Growth Factors" (TGF beta)," Fibroblast Growth Factor" (FGF), interleucinas e osteoprotegerina (38-45), que é um fator inibidor da osteoclastogênese.

Os genes que determinam a síntese do colágeno tipo I alfa, quando sofrem mutações, resultam nos vários tipos clínicos da Osteogenesis Imperfecta (39). Embora estas mutaçooes nos genes responsáveis pela síntese do colágeno não tenham sido encontradas nos indivíduos con osteoporose, o polimorfismo de uma região envolvida na transcrição genética está associada à diferenças na densidade mineral óssea e no risco de fraturas. J Sainz et al., em um trabalho publicado recentemente (40), observaram que o polimorfismo no sítio de restrição $S p l$ do gene do colágeno tipo I (COLIAl) está relacionado à menor massa óssea em meninas prépúberes, mesmo após correção para o tamanho das vértebras. No entanto, os mecanismos pelos quais as diferenças nos alelos afetam a massa óssea não estão esclu cidos. Alguns autores (16) sugerem que a síntese e a degradação do colágeno tipo I, que representa mais de 90\% do colágeno do osso, sejam geneticamente determinadas e que este fenômeno esteja relacionado à herança genética da densidade mineral óssea.

No tecido ósseo, tanto IGF-I quanto suas proteínas de ligação (IGFBPs) são sintetizadas pelo osteoblasto, sob controle do GH e de outros fatores endócrinos e autócrinos. IGF-I, por outro lado, regula a proliferação e diferenciação do osteoblasto e a síntese do colágeno, participando de forma importante no processo de remodelação óssea.
Bilezikian et al. publicaram recentemente o achado de níveis circulantes reduzidos de IGF-I em homens com osteoporose idiopática $(46,47)$, sem alterações na secreção de $\mathrm{GH}$, indicando que outros fatores devem participar da regulação da expressão de IGF-I.

Fatores genéticos também podem regular várias funções fisiológicas associadias ao acímulo de massa óssea durante o crescimento. Dois mecanismos adaptativos que controlam o metabolismo do cálcio e fósforo parecem ser muite importantes neste período, como o aumento dos níveis de calcitriol ( $1-25 \mathrm{OHD} 3$ ) e o estímulo à reabsorçio tubular de fosfato. O aumento da síntese de calcitriol permite maior absorção intestinal de cálcio e fósforo, necessários à maior demanda do período de estirão de crescimento (48). Estudos recentes (49) sugerem que a IGF-I scria responsável pelo estímulo à síntese de calcitriol c aumento da reabsorção renal de fósforo. Os níveis de IGF-I, calcitriol e fósforo aumentam na puberdade, estando correlacionados com os níveis de osteocalcina (50). O pico de secreção de osteocalcina coincide com o de IGF-l e com o estiräo de crescimento.

\section{Fatores antropométricos}

Em crianças pré-púberes, há uma grande correlação entre massa óssci na coluna lombar e no fêmur com a altura (3). No cntanto, esta estreita correlação atenuase durante a maturação sexual, aproximando-se do padrão observado em adultos. Isto significa que parte dos determinantes do pico de massa óssea durante a puberdade agem de forma independente dos fatores relacionados ao ganho estatural.

Cadogan et al. (51) observaram, através de um estudo longitudinal $\mathrm{cm}$ meninas púberes, uma dissociação entre o estirão de crescimento e o ganho de massa óssea do corpo inteiro. Não houve correlação entre os dois parâmetros e o ganho de altura não foi preditivo do ganho de massa óssea.

O pico na velocidade de ganho estatural ocorreu dois anos antes da menarca, enquanto que o pico de incremento na massa óssea coincidiu com a menarca. Estes dados foram confirmados por outros autores $(4,6)$ e talvez possam explicar a susceptibilidade das crianças em estirão à fraturas com mínimos traumas.

Desde o início da $3^{a}$ década de vida, em ambos os sexos, há uma enorme variabilidade nos valores normais do conteúdo mineral ósseo (BMC) e da densidade mineral óssea (BMD), que não aumentam mais significativamente com a idade. Esta variação, que é observada tanto no esqueleto axial quanto no apendicular, mantém-se mesmo corrigindo para a altura do indivíduo. Em adultos jovens, a variação de BMC de coluna lombar (L2L4) é de quatro a cinco vezes maior que a variaçăo de altura. 
Esta variação, independente da altura, aumenta durante a puberdade em sítios ósseos onde o acúmulo de massa óssea é acentuado neste período, como a coluna lombar e o colo femural. Por outro lado, em locais onde o aumento da massa óssea pubertário não é tão pronunciado, como a diáfise femural, a variação permanece constante em relação à variação estatural.

O peso corporal tem sido sempre associado positivamente à massa óssea (2), sendo um dos mais importantes fatores na predição da densidade e do conteúdo mineral ósseo. Os dois maiores componentes do peso corporal, massa muscular e massa de gordura, estão correlacionados com o ganho de densidade mineral total no esqueleto, embora o músculo tenha o maior valor preditivo segundo alguns autores (52-57). Faulkner et al. (53), estudando a composição corporal pelo método da densitometria por DxA, em crianças de oito a dezesseis anos, observou que a massa magra tem o maior valor preditivo para a massa óssca. Vários mecanismos podem estar implicados nesta estreita associação entre massa óssea e magra, como as forças musculares aplicadas ao osso, determinantes genéticos comuns e mediadores hormonais anabólicos tanto para o osso quanto para o músculo, como GH, andrógenos e insulina (58).

Indivíduos adultos obesos tendem a apresentar valores mais elevados de BMD que indivíduos magros. Frost, em uma revisão crítica sobre o assunto (59), esclarece que esta associação só é observada quando a massa gordurosa exerce forças mecânicas sobre o tecido ósseo. Se o obeso é sedentário, como ocorre em inúmeras condições clínicas associadas à obesidade do adulto, a força e massa musculares reduzidas podem levar à osteopenia.

Em um estudo realizado em 416 adolescentes (60), entre 10 e 18 anos de idade, estudantes de uma escola particular de São Paulo, observamos que o Estadiamento Puberal, a idade e o peso foram as variáveis mais correlacionadas aos valores de BMD na coluna lombar, colo de fêmur, fềmur total e BMD total. Como a massa magra apresenta uma alta correlação com o peso $(\mathrm{r}=0,80$ e $\mathrm{r}=0,88$, respectivamente para o sexo feminino e masculino), sendo o seu maior componente, quando exclúmos o peso como variável da regressão múltipla, tanto a massa de gordura quanto a massa magra passaram a ser variáveis significativas. $\mathrm{Na}$ verdade, os parâmetros antropométricos estão tão fortemente inter-relacionados que a retirada de um deles modifica a importância dos demais. Outros autores também comentam este interessante problema de análise $(11,61)$.

Para esta população adolescente estudada, não puciemus conciluir que a massa muscular seja um fator preditor de massa óssea mais importante que o peso, como é descrito por outros autores em adultos (1.1) e crianças (53). No entanto, nossos dados parecem indicar que o grupo é bastante ativo fisicamente, de modo que tanto peso quanto massa muscular são igualmente importantes.

Ainda persiste a idéia de que, para ambos os sexos, em qualquer raça c em qualquer sítio ósseo, o pico de aquisição de massa óssea ocorra na $3^{a}$ e $4^{\text {a }}$ décadas. Este conceito surgiu de alguns estudos transversais feitos no antebraço, utilizando métodos de "Single Photon Absorptiometry", anteriores ao "Dual energy $x$-ray absorptiometry" ou DxA. No entanto, são inúmeros os trabalhos que demonstram não haver aumento significativo durante a $3^{\text {a }}$ década. Na verdade, para o fềmur proximal, vários autores encontraram uma tendência à perda já a partir dos 30 anos $(6,62,63)$.

\section{Fatores sexuais}

A puberdade é o período no qual as diferenças relacionadas ao sexo se tornam evidentes. Na verdade, no período pré-pubertário, năo existem diferenças significativas entre a massa óssea de ambos os sexos, seja no esqueleto apendicular ou axial $(3,64)$.

Esta ausência de diferença sexual se mantém até o início da puberdade. Entre 12 e 15 anos, as meninas tendem a ter valores de $\mathrm{BMD}\left(\mathrm{g} / \mathrm{cm}^{2}\right)$ mais elevados do que os meninos, particularmente na coluna lombar (L2L4). Este incremento na coluna lombar ocorre particularmente, num período de três anos, sendo que a maioria dos autores concorda que a menarca e os meses subsequentes correspondam ao pico de aquisição de massa óssea neste sítio. O desenvolvimento sexulal no sexo feminino ocorre mais precocemente e tem uma duração menor quando comparado ao sexo masculino, correlacionando-se com as diferenças de BMD observadas entre os 1 I e 15 anos. Além disso, os meninos apresentam tuma área vertebral proporcionalmente maior, contribuindo para diminuir a BMD neste período.

No grupo de adolescentes por nós estudado (60), não observamos diferenças significativas entre os sexos, exceto na BMD da coluna lombar. Quando agrupamos os dados por estadiamento puberal, meninos e meninas apresentam o mesmo comportamento em relação ao ganho de massa óssea nos sítios femurais e na BMD total, embora em idades cronológicas diferentes. Coincidente com a literatura, nossos resultados sugerem que o período de maior ganho ósseo ocorra entre o estadiamento II e III de Tanner, como podemos demonstrar nas figuras $1 \mathrm{e} 2$. Os efeitos da puberdade mais precoce nas meninas e da maior susceptibilidade das vértebras, 


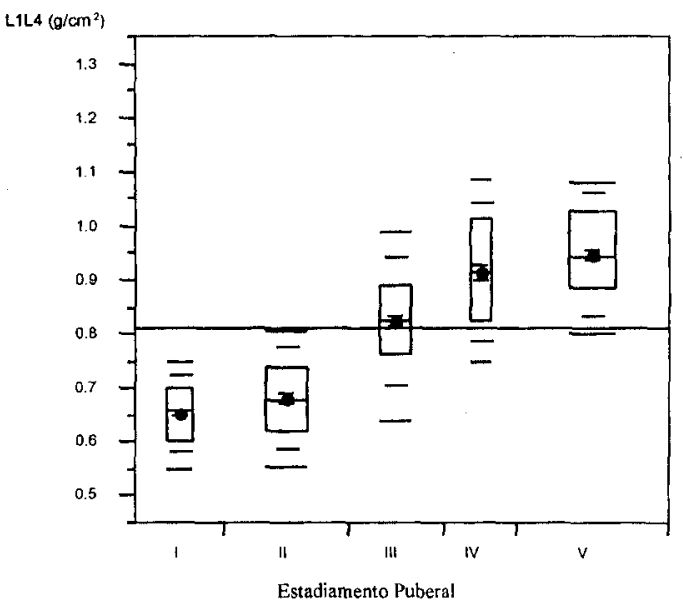

Figura 1: Resultados da BMD de LlL4 $\left(\mathrm{g} / \mathrm{cm}^{2}\right)$ por Estadiamento Puberal, no total da amostra de 416 adolescentes. entre 10 e 18 anos, em gráfico Box Plot. As caixas representam $\circ 25^{\circ}$ e $75^{\circ}$ quartis, com a média do grupo em um circulo preenchido e os correspondentes erros padrão, $010^{\circ}$ $90^{\circ}$ percentis estão representados pelas linhas mais distantes, enquanto que as linhas próximas representam dois desvios padrão

pelo predomínio de osso trabecular, à ação dos esteróides sexuais, devem contribuir para as diferenças de BMD em coluna lombar observada entre os sexos.

\section{Diferenças raciais}

A prevalência de Osteoporose e a incidência de fraturas apresentam grande variação entre as raças e entre países de um mesmo continente com a mesma distribuição racial. As fraturas femurais e vertebrais são significativamente menos incidentes na população negra do que na branca, enquanto que os asiáticos fraturam menos que os brancos mesmo tendo valores menores de BMD. Estas características são atribuídas a diferenças raciais na geometria e tamanho dos ossos axiais e apendiculares, diferenças raciais também nas medidas antropométricas e na densidade óssea, variações na dieta e nas atividades habituais e outros fatores culturais. Estes fatores podem alterar a susceptibilidade a fraturas e podem ser observados desde a infância $(65,66)$.

As crianças negras apresentam maior comprimento dos membros inferiores em relação ao tronco, comparadas às crianças brancas. A raça negra apresenta áreas de secção dos ossos longos maiores, independente do estádio puberal e da altura, conferindo maior estabilidade estrutural. Quanto à coluna lombar, a raça negra apresenta altura dos corpos vertebrais menores que os indivíduos brancos, mas com as mesmas áreas de seç̧ão, e a densidade mineral óssea é maior a partir do final da puberdade (67).

Este maior acúmulo de massa óssea observado

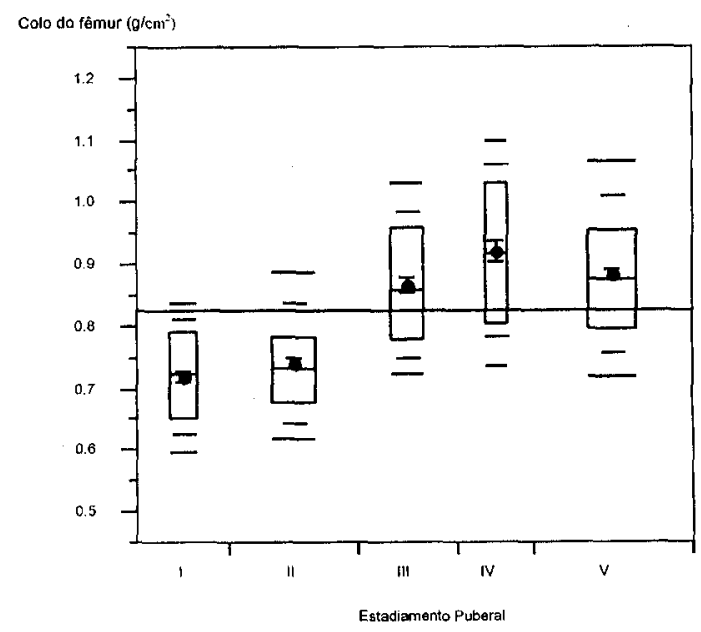

Figura 2: Resultados da BMD do LIL4 Colo Femural por Estadiamento Puberal, no total da amostra de 416 adolescentes. entre 10 e 18 anos, em gráfico Box Plot. As caixas representam o $25^{\circ}$ e $75^{\circ}$ quartis, com a média do grupo em um circulo preenchido e os correspondentes erros padrão. $010^{\circ} 90^{\circ}$ percentis estão representados pelas linhas mais distantes, enquanto que as linhas próximas representam dois desvios padrão

na raça negra, deve estar relacionado à maior reabsorção renal de cálcio e resistência à ação reabsortiva do PTH no osso, que são descritas por alguns autores $(68,69)$. Segundo estes trabalhos, os indivíduos negros apresentam níveis menores de osteocalcina, da fração óssea da fosfatase alcalina e da hidroxiprolina urinária.

A incidência de fraturas, observada na maioria das populações asiáticas, é menor que a registrada nos países ocidentais, apesar de apresentarem massa óssea e Índice de Massa Corpórea menores. Este fato está provavelmente relacionado a fatores culturais, hábitos de vida e à geometria do quadril, pois os asiáticos apresentam medidas menores do eixo do colo do fêmur em comparação com a população branca (70). O tamanho do eixo do colo do fêmur, que é a distância entre a região acetabular e a base do trocanter maior, além de outras medidas do fềmur proximal, são fatores de risco para ocorrência de fraturas de colo e trans-trocantéricas.

\section{Atividade física e hábitos alimentares}

Inúmeros trabalhos confirmam uma correlação significativa entre a massa muscular e a densidade mineral óssea do indivíduo, observada em vários sítios ósseos (11,54-57), mesmo em indivíduos sedentários. Crianças e adolescentes que participam de atividades esportivas competitivas têm melhor massa óssea do que jovens com menor atividade fisica. Kriska et al. (71), estudando mulheres adultas, observaram que a BMD não se associava à atividade física recente mas com o padrão de atividade física exercido entre os 14 
e 21 anos de idade. Estes dados reforçam a importância de se aumentar a atividade fisica dos jovens para otimizar o pico de massa óssea.

Segundo Arden et al. (8), a massa muscular pode explicar de 6 a $16 \%$ da variância da BMD, dependendo do sítio ósseo estudado. Outros autores $(54,56)$ demonstraram que a força muscular está igualmente associada com a BMD dos sítios ósseos próximos do local de ação do músculo avaliado como dos sítios ósseos distantes. Este fenômeno sugere que a correlação não seja apenas devido a fatores biomecânicos, mas a fatores envolvidos na determinação da força muscular geral. Estes fatores que agem conjuntamente na BMD e na massa muscular são provavelmente ambientais, como o exercício físico, endócrinos e genéticos.

Inúmeras investigações sobre o efeito da ingesta de cálcio sobre a BMD, em diversas fases da vida, são discordantes (72-75). Estes achados inconsistentes podem ser atribuídos a falhas metodológicas, como por exemplo, a avaliação da ingesta em certo momento não identifica variações que tenham ocorrido ao longo do tempo.

Outros componentes da dieta, como fósforo e proteína, além do valor calórico ingerido, podem ter um efeito benéfico sobre a aquisição da massa óssea c raramente são avaliados. Entretanto, alguns estudos prospectivos em crianças e adolescentes, com suplementação de cálcio da dieta, observaram um aumento na densidade mineral óssea em relação aos grupos que receberam placebo (76-78). É interessante observar que a influência genética exerce efeitos diferentes no osso cortical e no osso trabecular, sendo este último menos afetado pelo tamanho dos ossos ou pela ingesta de cálcio. Bonjour et al. (73), estudando meninas pré-púberes que receberam suplementação de cálcio da dieta, obtiveram melhores resultados em diáfise dos ossos apendiculares do que na coluna lombar.

\section{REFERÊNCIAS}

1. Matkovic V, Jelic T, Wardlaw GM, llich IZ, Goel PK, Wright $\mathrm{JK}$, ef al. Timing of peak bone mass in Caucasian females and its implication for the prevention of Osteoporosis. J Clin Invest 1994;93:799-808.

2. Teegarden D. Proulx WR, Martin BR, Zhao J, McCabe GP. Lyle RM, et al. Peak bone mass in young women. J Bone Miner Res 1995; 10:711-5.

3. Bonjour JP. Theintz $G$, Buchs B, Slosman D, Rizzoli R. Critical years and stages of puberty for spinal and femoral bone mass accumulation during adolescence. J Clin Endocrinol Metab 1991;73:555-63.

4. Lu PW. Briody JN, Ogle GD, Morley K, Humphries IRJ, Allen $\mathrm{J}$, et al. Bone mineral density of total body, spine and femoral neck in children and young adults: a crosssectional and longitudinal study. J Bone Miner Res
1994:9:1451-8.

5. Sabatier JP, Guaydier-Souquières $G$, Laroche D, Beumalek A, Fournier L, Guillon-Metz $F$, et al. Bone mineral acquisition during adolescence and early adulthood: A studying 574 healthy females $10-24$ years of age. Osteoporosis int 1996;6:141-8.

6. Theintz G, Buchs B, Rizzoli R, Slosman D. Clavieu H. Sizonenko Pc, et al. Longitudinal monitoring of bone mass accumulation in healthy adolescents - Evidence for a marked reduction after 16 years of age at the levels of lumbar spine and femoral neck in female subjects. J Clin Endocrinol Metab 1992;75:1060-5.

7. Arden NK, Baker I, Hoog C, Boan K, Spector TD. The heritability of bone mineral density, ultrasound of the calcaneus and hip axis length: a study of postmenopausal twins. J Bone Miner Res 1996; 1 1:530-4.

8. Arden NK. Spector TD. Genetic influences on muscle strength, lean body mass, and bone mineral density: a twin study. J Bone Miner Res 1997: 12:2076-81.

9. Garnero P. Arden NK, Griffiths G, Delmas P-D, Spector TD. Genetic influence on bone furnover in postmenopausal twins. J Clin Endocrinol Metab 1996:81:140-6.

10. Guéguen R, Jouanny P, Guilhemin F, Kuntz C. Pourel J, Siest $G$. Segregation analysis and variance components analysis of bone mineral density in heaithy families. J Bone Miner Res 1995; 10:2017-22.

11. Krall EA, Dawson-Hughes B. Soft tissue body composition: familiat resemblance and independent influences on bone mineral density. J Bone Miner Res 1995; 10: 1944-50.

12. Howard GM, Nguyen TV, Harris M, Kelly PJ, Eisman JA. Genetic and environmental contributions to the association between quantitative ultrasound and bone mineral measurements: a twin study. J Bone Miner Res 1998; 13:1318-27.

13. Seeman E, Tsalamandris C, Formica C, Hopper JL. Mckay J. Reduced femoral neck bone density in the daughters of women with hip fractures: the role of low peak bone density in the pathogenesis of osteoporosis. J Bone Miner Res 1994:9:739-43.

14. Ferrari S, Rizzoli R, Slosman D, Bonjour PJ. Familial resemblance for bone mineral mass is expressed before puberty. J Clin Endocrinol Mefab 1998;83:358-61.

15. Pocok NA, Eisman JA, Hopper JC, Yeats MG, Sambrook PN, Eberl S. Genetic determinants of bone mass in adults: a twin study. J Clin Invest 1987;80:706-10.

16. Slemenda CW. Christian JC, Williams CJ, Norton JA, Johnston CJ. Genetic determinants of bone mass in adult women: a reevaluation of the twin model and the potential importance of gene interaction on heritability estimates. J Bone Miner Res 1991;6:56 1-7.

17. Kelly PJ, Hopper JL, Macaskill GT, Pocok NA, Sambrook PN, Eisman JA. Genetic factors in bone turnover. J Clin Endocrinol Metab 1991;72:808-13.

18. Tokita A, Kelly PJ, Nguyen TV, QI JC, Morrison NA, Risteli $L$, et al. Genetic influences on type I collagene synthesis and degradation: further evidence for genetic regulation of bone turnover. J Clin Endocrinol Metab 1994:78:1461-6.

19. Morrison NA, QI JC, Tokita A, Kelly PJ, Crofts L, Nguyen TV, et al. Prediction of bone density from vitamin D receptor alleles. Nature 1994:367:284-7. 
20. Fleet JC, Harris SS, Wood RJ, Dawson-Hughes B. The Bsml vitamin $D$ receptor restriction fragment length polymorphism (BB) predicts low bone density in premenopausal black and white women. J Bone Miner Res 1995;10:985-90.

21. Riggs BL, Nguyen TV, Melton L. The contribution of vitamin $D$ receptor gene alleles to the determination of bone mineral density in normal and osteoporotic women. J Bone Miner Res 1995; 10:991-6.

22. Salamone LM, Ferrell R, Black DM, Palermo L, Epstein RS, Petro $N$, ef al. The association between vitamin $D$ receptor gene polymorphisms and bone mineral density at the spine, hip and whole-body in premenopausal women. Osteoporosis Int 1996:6:63-8.

23. Ferrari S, Rizzoli R, Chevalley T, Slosman D, Eisman JA, Bonjour JP. Vitamin D receptor gene polymorphisms and change in lumbar-spine bone mineral density. Lancet 1995:345:423-4.

24. Yamagata Z, Miyamura T, Lijima S, Asaka A, Sasaki M, Kato J, et al. Vitamin $D$ receptor gene polymorphism and $B M D$ in healthy Japanese women. Lancet 1994;344:1027.

25. Garnero P. Borel O. Sornay-Rendu E, Delmas PD. Vitamin $D$ receptor gene polymorphisms do not predict bone turnover and bone mass in healthy premenopausal women. J Bone Miner Res 1995: 10: 12.83-8.

26. Garnero P, Borel O, Sornay-Rendu E, Arlot ME, Delmas PD. Vitamin D receptor gene polymorphisms are not related to bone turnover, rate of bone loss, and bone mass in postmenopausal women. The OFELY study. J Bone Miner Res 1996;1 1:827-34.

27. Jorgenesen HL, Scholler J, Sand JC. Bjuring M. Hasseger $C$. Christiansen $C$. Relation of common allelic variation at vitamin $D$ receptor locus to bone mineral density and postmenopausal bone loss: cross sectional and longitudinal population study. Br Med J 1996:313:586-90.

28. Ensrud KE, Stone K, Cauley JA, White C, Zmuda JM Nguyen TV, et al. Vitamin D Receptor Gene Polymorphisms and the Risk of Fractures in Older Women. J Bone Miner Res 1999; 14: 1637-45.

29. Cooper GS. Genetic Studies of Osteoporosis: What Have We Learned? J Bone Miner Res 1999:14:1646-8.

30. Castro ML, Oliveira MD, Russo EK, Vieira JGH. Vitamin D receptor alleles and $B M D$ in a normal premenopausal Brazilian female population. Braz J Med Biol Res 1997;30:929-32

31. Ramalho AC, Castro ML, Hauache O, Kasamatsu T, Brandao CMA, Reis AS, et al. Fracture of the proximal Femur: Correlation with Vitamin D polymorphism. Braz J Med Biol Res 1998:31:921-7.

32. Hauache O, Castro ML, Andreoni S, Gimeno SGA, Brandao CMA, Ramalho AC, et al. Vitamin D receptor Gene polymorphism: correlation with BMD in a brazilian population with insulin-dependent Diabettes Mellitus. Osteoporosis Int 1998:8:204-10.

33. Genenari L, Becherini L, Mási L, Mansani R, Gonnelli S, Cepollaro $C$, ef al.Vitamin $D$ and estrogene receptor allelic variants in Italian postmenopausal women: evidence of multiple gene contribution to bone mineral density. J Clin Endocrinol Metab 1998;83:939-44.

34. Kobaashi S, Inoue S, Hosoi T, Ouchi Y, Shiraki M, Orimo H Association of BMD with polymorphism of the estrogene receptor gene. J Bone Miner Res 1996;11:306-11.

35. Bodine PVN, Henderson RA, Green J. Aronow M, Owen
T. Stein GS, et al. Estrogene receptor is developmentally regulated during osteoblast differentiation and contributes to selective responsiveness of gene expression. Endocrinology 1998; 139:2048-57.

36. Stein GS, Lian JB. Molecular machanisms mediating proliferation/differentiation interrelationships during progressive development of the osteoblast phenotype. Endocr Rev 1993; 14:424-42

37. Smith EP. Boyd J, Frank GR. Estrogene resistance caused by a mutation in the estrogene-receptor gene in a man. N Engl J Med 1994;331:1056-61.

38. Grant SFA, Reid DM, Blake G, Herd R, Fogelman I, Ralston SH. Reduced bone density and Osteoporosis assoclated with a polymorphic Spl binding site in the collagene type I alpha 1 gene. Nature Genet 1996;14:203-5.

39. Uitterlinden $A G$, Burger $H$, Huang $Q$, Yue F, McGuigan FEA, Grant SFA, et al. Relation of alleles of the collagene type I alpha 1 gene to bone density and the risk of osteoporotic fractures in postmenopausal women. $\mathrm{N}$ Engl J Med 1998:338:1016-21.

40. Sainz J, van Tornout JM, Sayre J, Kaufman F, Gilsanz V. Association of Collagene Type I alpha 1 gene polymorphism with Bone Density in Early Childhood. J Clin Endocrinol Metab 1999:84(3):853-5.

41. Mizunuma $H$, Hosoi $T$, Okano $H$, Soda $M$, Tokizana $T$, Kagami l, et al. Estrogene receptor gene polymorphism and BMD at the lumbar spine of the pre and postmenopausal women. Bone 1997:21:379-83

42. Masi L, Becherien L, Genenari L, Colli E, Mansani R, Tanini $A$, ef al. Allelic variants of human calcitonin receptors: distribution and association with bone mass in postmenopausal Italian women. Biochem Biophys Res Commun 1998;245:622-6.

43. Lorenzo JA, Naprta A, Rao Y, Alander C, Glaccum M, Widmer $M$, et al. Mice lacking the type I interleukin-1 receptor do not lose bone mass after ovariectomy. Endocrinol 1998; $139: 3022-5$

44. Mizuno A, Amizuka N, Irie K, Murakami A, Fujise N, Kanno T, et al. Severe osteoporosis in mice lacking osteoclastogenesis inibitory factor/osteoprotegerin. Biochem Biophys Res Commun 1998:247:610-5.

45. Rosen CJ, Kurland ES, Vereault D. Adler RA, Rackoff PJ, Craig $W Y$, et al. Association between serum insulin growth factor I (IGF-I) and a simple sequence repeat in IGF-1 gene: implications for genetic studies of bone mineral density. J Clin Endocrinol Metab 1998;83:2286-90.

46. Kurland ES, Chan F, Vereault D, Rosen CJ, Bilezikian JP. Normal growth hormone secretory reserve in men with idiopathic osteoporosis and reduced circulating levels of IGF-1. J Clin Endocrinol Metab 1998:83:2576-9.

47. Kurland ES, Rosen CJ, Cosman F. IGF- 1 in mem with idiopathic osteoporosis. J Clin Endocrinol Metab 1997:82:2799-805.

48. Bonjour JP, Theintz G. Law F, Slosman D, Rizzoli R. Peak of Bone Mass. Osteoporosis Int 1994;Suppl 1:507-13.

49. Caverzario J, Bonjour JP. IGF-. , a key regulator of renal phosphate transport and 1-25-dihydroxyvitamin $D_{3}$ production during growth. News Physiol Sci 1991;6:206-10.

50. Johansen JS, Giwercman A, Hartwell D, Nielsen GT, Price PA, Christiansen C, ef al. Serum bone-Gla protein as a marker of bone growth in children and adolescents: correlation with age, height, IGF-1 and serum testosterone. 


\section{J Clin Endocrinol Metab 1988;67:273-8.}

51. Cadogan J, Blumsohn A, Barker ME, Eastell R. A longitudinal study of bone gain in pubertal girls: anthropometric and biochemical correlates. J Bone Miner Res 1998; 13:1602-12.

52. Slemenda CW, Reister TK, Hui SL, Miller JZ, Christian JC, Johnston CC. Influences on skeletal mineralization in children and adolescents: evidence for varying effects of sexual maturation and physical activity. J Pediatr 1994:125:201-7.

53. Faulkner RA, Bailey DA, Drinkwater DT, Wilkinson AA, Houston CC. Mckay HA. Regional and total body bone mineral content, bone mineral density, and total body tissue composition in children 8-16 years of age. Calcif Tissue Int 1993;53:7-12.

54. Henderson NK, Price Rl, Cole JH, Gutteridge DH, Bhagat Cl. Bone density in young women is associated with body weight and muscle strength but not dietary intakes. J Bone Miner Res 1995; 10:384-93.

55. Lindsey R, Cosman F, Herrington BS, Himmelstein S. Bone mass and body composition in normal women. J Bone Miner Res 1992;7:55-63.

56. Pocock N. Eisman J, Gwinn T, Sambrook P, Kelly P. Freund $J$, et al. Muscle strength, physical fitness and weight but not age predict femoral neck bone mass. J Bone Miner Res 1989:4:441-8.

57. Bradney M. Pearce $G$, Naughton $G$, Sullivan $C$, Bass $S$, Beck T, et al. Moderate exercise during growth in prepubertal boys changes in bone mass, size, volumetric density and bone strength: a controlled prospective study. J Bone Miner Res 1998:13:1814-21.

58. Slemenda CW. Editorial: Body Composition and Skeletal Density-Mechanical loading or something more? J Clin Endocrinol Metab 1995;80:1761-3.

59. Frost HM Obesity, and bone strength and mass: a tutorial based on insights from a new paradigm. Bone 1997:21(3):211-4

60. Brandão CMA. Avaliação da densidade mineral óssea durante a puberdade, em crianças normais de São Paulo. Influência de Fatores Antropométricos, Composição Corporal e do SDHEA na Massa Óssea. Tese apresentada à Universidade Federal de São Paulo (UNIFESP - EPM) para obtenção do título de Doutor em Medicina. São Paulo, 1999

61. Katzman DK, Bachrach LK, Carter DR, Marcus R. Clinical and anthropometric correlates of bone mineral acquisition in healthy adolescent girls. J Clin Endocrinol Melab $1991 ; 73(6): 1332-9$.

62. Rodin A, Murby B. Smith MA, Caleffi M, Fentiman I, Chapman MG, et al. Premenopausal bone loss in the lumbar spine and neck of temur: a study of 225 Caucasian Women. Bone 1990;11:1-5.

63. Riggs BL, Wahner HW, Melton LJ III, Richelson LS, Judd HL, Offord KP. Rate of bone loss in the appendicular and axial skeletons of women: evidence of substantial vertebral bone loss before menopause. J Clin Invest 1986;77:1487-91.

64. Glastre C, Braillon P. David L, Cochat P, Meunier PJ, Delmas $\mathrm{PD}$. Measurement of bone mineral content of the lumbar spine by DEXA in normal children: correlation with growth parameters. J Clin Endocrinol Metab 1990;70:1330-3

65. Li JY, Specker BL, Ho ML, Tsang RC. Bone mineral content in black and white children 1 to 6 years of age. Early appearance of race and sex differences. Am J Dis Child 1989; 143:1346-9.

66. McCormick DP, Ponder SW, Fawcett HD, Palmer IL. Spinal bone mineral density in 335 normal and obese children and adolescents: evidence for ethnic and sex differences. J Bone Miner Res 1991;6:507-13.

67. Gilsanz Vskaggs DL, Kovanlikaya A, Sayre J, Loro ML, Kaufman F, Korenman SG. Differential affect of race on the axial and appendicular skeletons of children. J Clin Endocrinol Metab 1998:83:1420-7.

68. Meier DE, Luckey MM, Wallenstein S, Clemens TL, Orwoll ES, Waslien CL. Calcium, vitamin D and parathyroid hormone status in young white and black women: association with racial differences in bone mass. J Clin Endocrinol Metab 1991;72:703-10.

69. Kleerekoper M. Nelson DA, Peterson EL, Flynn MJ, Pawluszka AS, Jacobsen $G$, et al. Reference data for bone mass, calciotropic hormones, and bjochemical markers of bone remodeling in older (55-75) postmenopausal white and black women. J Bone Miner Res 1994:9:1267-6.

70. Chin K, Evans MC, Cornish J, Cundy T, Reid IR. Differences in hip axis and femoral neck length in premenopausal women of polynesian, asian and european origin. Osteoporosis Int 1997;7:344-7.

71. Kriska AM, Sandler RB, Cauley JA, LaPorte RE, Hom DL Pambianco $G$. The assessment of historical physical activity and its relation to adult bone parameters. Am J Epidemiol 1988; 127:1053-63.

72. Dawson-Hughes B. Calcium supplementation and bone loss: a review of controlled clinical trials. Am J Clin Nufr 1991:54:274S-80S.

73. Bonjour JP, Carrie AL, Ferrari S. Calcium-enriched foods and bone mass growth in prepubertal girls: a randomized double-blind, placebo-controlled trial. J Clin Invest 1997:99:1287-94.

74. Reid IR, Ames RW, Evans MC, Gamble GD, Sharpe SJ. Effect of calcium supplementation on bone loss in postmenopausal women. N Engl J Med 1993:328:460-4.

75. Baran D, Sorensen A, Grimes J, Lew R, Karellas A, Johnson $B$, et al. Dietary modification with dairy products for preventing vertebral bone loss in premenopausal women: a three year prospective study. J Clin Endocrinol Metab 1990;70:264-70.

76. Johnston CC Jr, Miller ZZ, Slemenda CW, Reister TK, Hui S, Christian JC, et al. Calcium supplementation and increases in bone mineral density in children. $N$ Engl J Med 1992;327:82-7

77. Lloyd T, Andon MB, Rollings N. Martel JK, Landis JR, Demers LM, et al. Calcium supplementation and bone mineral density in adolescent girls. JAMA 1993;270:841-4.

78. Lee WTK, Leung SSF, Wang SH, XU YC, Zeng WP, Lau J, et al. Double-blind controlled calcium supplementation and bone mineral accretion in children accustomed to low calcium diet. Am J Clin Nutr 1994;60:744-50.

\section{Endereço para correspondência:}

Cynthia MA Brandão

Disciplina de Endocrinologia e Metabologia, UNIFESP - EPM

Caixa Postal 20266

04034-970 São Paulo, SP

E-mail: cynthia.brandao@fleury.com.br 